\title{
Intensity of end-of-life health care and mortality after systemic anti-cancer treatment in patients with advanced lung cancer
}

\author{
Kersti Oselin ${ }^{1 *}\left(\mathbb{D}\right.$, Heti Pisarev², Keit llau ${ }^{3}$ and Raul-Allan Kiivet ${ }^{2}$
}

\begin{abstract}
Background: We aimed to study the mortality and intensity of health care in patients with advanced lung cancer who received systemic anti-cancer treatment (SACT) compared with patients who were not eligible for SACT (no-SACT).

Methods: A retrospective cohort of patients with lung cancer, who were treated at the North Estonia Medical Centre from 2015 to 2017, was linked to population-based health care data from the Estonian Health Insurance Fund. We calculated 14- and 30-day mortality after SACT and used a composite measure of intensity of care, comprised from the following: emergency department visit, admission to hospital, admission to intensive care unit, receipt of radiotherapy or systemic treatment.

Results: The median overall survival (OS) of patients who received at least one cycle of SACT $(n=489)$ was 9.1 months and in patients with no-SACT $(n=289) 1.3$ months (hazard ratio $[\mathrm{HR}]=4.23,95 \% \mathrm{Cl}=3.60-5.00$ ). During the final 30 days of life, intensive EOL care was received by $69.9 \%$ of the SACT patients and $43.7 \%$ of the no-SACT patients. Intensive EOL care in the last 30 days of life is more probable among patients in the SACT group (odds ratio $[\mathrm{OR}]=3.58,95 \% \mathrm{Cl}=2.54-5.04, p<0.001$ ), especially in those with a stage IV disease $(\mathrm{OR}=1.89,95 \% \mathrm{Cl}=1.31-2.71, p=0.001)$. In the SACT group 6.7 and $14.7 \%$ of patients died within 14 days and 30 days after the last cycle, respectively.

Conclusions: Significant proportion of patients with advanced lung cancer continue to receive intensive care near death. Our results reflect current patterns of EOL care for patients with lung cancer in Estonia. Availability of palliative care and hospice services must be increased to improve resource use and patientoriented care.
\end{abstract}

Keywords: Advanced lung cancer, End-of-life care, High intensity care

\footnotetext{
* Correspondence: kersti.oselin@regionaalhaigla.ee

'Department of Chemotherapy, Clinic of Haematology and Oncology, North Estonia Medical Centre, J. Sütiste tee 19, 13419 Tallinn, Estonia

Full list of author information is available at the end of the article
}

(c) The Author(s). 2021 Open Access This article is licensed under a Creative Commons Attribution 4.0 International License, which permits use, sharing, adaptation, distribution and reproduction in any medium or format, as long as you give appropriate credit to the original author(s) and the source, provide a link to the Creative Commons licence, and indicate if changes were made. The images or other third party material in this article are included in the article's Creative Commons licence, unless indicated otherwise in a credit line to the material. If material is not included in the article's Creative Commons licence and your intended use is not permitted by statutory regulation or exceeds the permitted use, you will need to obtain permission directly from the copyright holder. To view a copy of this licence, visit http://creativecommons.org/licenses/by/4.0/. The Creative Commons Public Domain Dedication waiver (http://creativecommons.org/publicdomain/zero/1.0/) applies to the data made available in this article, unless otherwise stated in a credit line to the data. 


\section{Background}

The intensity of treatment towards the end of life (EOL) has been suggested as one of the factors most affecting quality of life (QoL) in patients with advanced cancer [1,2]. Intensive care at the EOL is variably defined in literature. In 2003, Earle and colleagues were first to identify several markers of potentially overly aggressive EOL cancer care, later several studies supported these conclusions [3-5]. The internationally recognised intensity of care and quality of EOL care indicators in oncology are: intensive use of systemic anti-cancer treatment (SACT), low rates of hospice use, ED visits, hospitalisations and admissions to ICU; all measures occurring within 14 or 30 days of death [6-8]. These service-based indicators could easily be applied to existing administrative data to assess the utilisation of health care services at the EOL retrospectively.

ASCO's expert panel for the "Choosing Wisely" campaign identified the use of chemotherapy with unknown benefits and in patients with poor performance status as the most widespread unnecessary practice in oncology [9]. Studies have reported that $5-22 \%$ of patients with advanced stage cancer received SACT within 2 weeks of death and up to $55 \%$ in the last month of life $[10,11]$. Early post-treatment mortality may be associated with SACT-related toxicity. Previous studies assessing chemotherapy use at the EOL, however, have not always been able to discriminate between treatmentrelated and cancer-related mortality.

Despite recent developments in immunotherapy, conventional chemotherapy remains the cornerstone of the treatment of advanced stage lung cancer. Neutropenia and infectious complications are common and potentially life-threatening adverse effects of chemotherapy. As shown in the recent study by Whitney et al., the most common diagnoses resulting in unplanned hospitalisations through ED visits included infection or fever, and among patients with different solid tumours the rates were highest for lung cancer, with $5.2 \%$ of all cancerrelated hospitalisations being related to neutropenia or fever in the US $[12,13]$.

In Estonia, approximately 800 people annually are newly diagnosed with lung cancer [14]. In the current study, we aimed to characterise EOL care, health care intensity in the final 30 days of life and SACT-related mortality with an emphasis on infectious complications in patients with advanced stage lung cancer based on routine clinical data from the North Estonia Medical Centre's Thoracic Oncology Database. The Estonian Cancer Registry has been collecting data on cancer incidence and mortality since 1968, but in regard to anticancer treatment only surgery is captured. Particularly, data on palliative care in Estonia are lacking. We provide data that will inform oncologists and policymakers of the limitations in lung cancer care and should help them plan interventions to improve the quality of care.

\section{Methods \\ Study cohort}

This is a retrospective analysis of the health care data of patients with lung cancer treated at the North Estonia Medical Centre between 1 January 2015 and 31 December 2017. The North Estonia Medical Centre is the single provider of all types of oncology services for a population of 800,000 , and its Thoracic Oncology Database has covered all patients with lung cancer since 2015. During the study period, a multidisciplinary tumour board had confirmed treatment decisions of 1485 patients with lung cancer (Fig. 1). To identify the impact of palliative SACT, we excluded patients with lung cancer with local disease whose primary treatment was either surgery or radiotherapy, irrespective of whether this was combined with SACT; 111 patients excluded had either duplicate decisions or patient refusal of any investigations. This cohort contained 778 patients: 489 received SACT (SACT group) and 289 were not eligible to receive SACT (no-SACT group). The study was approved by the Tallinn Ethics Committee for Medical Research (no. 1972).

\section{Data sources}

Patient characteristics such as age, sex, stage, date of biopsy if performed, histology, disease status as newly diagnosed or recurrent and date of treatment decision were extracted from the Thoracic Oncology Database. The patient's national identification code from the Thoracic Oncology Database was linked to the electronic database of billing data of the Estonian Health Insurance Fund. This database incorporates detailed data on all medical services used during a hospital stay and any out-patient visits, including each cycle of SACT provided. To calculate the chemotherapy receipt within the last 14 and 30 days of life, the date of last cycle of SACT was linked to the date of death. The electronic data of patients who died within 14 and 30 days after the last cycle of SACT were reviewed in detail by two authors independently, and the probable cause of death related to progression and SACT-related toxicity such as sepsis, bacterial infection and neutropenia was identified. Data on the death, if applicable, was retrieved from the National Death Registry. The data cut-off date was 31 July 2018.

\section{Outcome measures}

The outcome measures to be assessed in this study were chosen on the basis of previous research. We analysed 


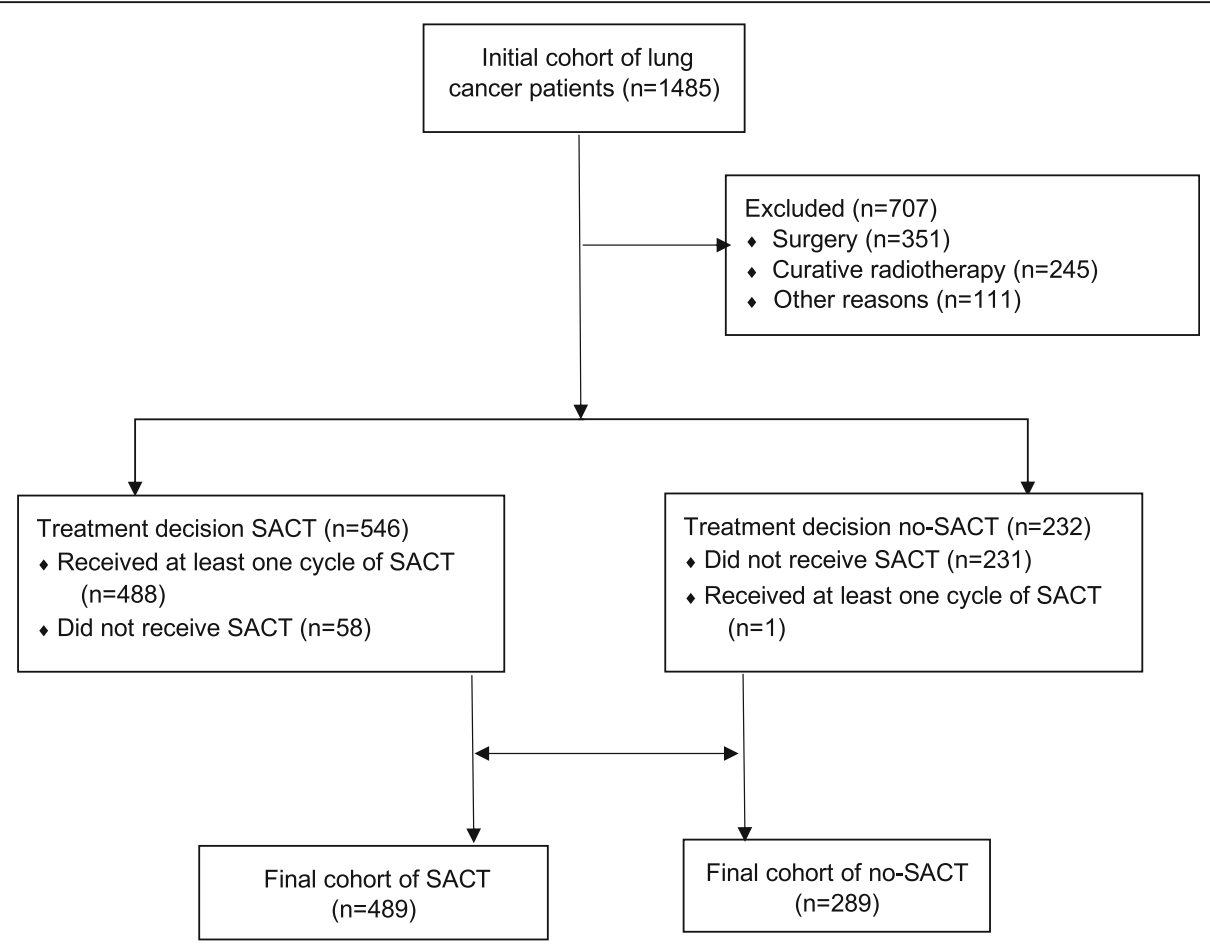

Fig. 1 Flow chart of the study population. Abbreviations: SACT, systemic anti-cancer treatment

health care utilisation and the circumstances of death, calculated 14- and 30-day mortality after SACT and used a composite measure of intensity of care, comprised from the following: emergency department visit, admission to hospital, admission to ICU, receipt of radiotherapy or systemic treatment (except no-SACT). For comorbidities in the whole cohort, we used only major diagnoses affecting chemotherapy administration such as diabetes (type 1 and 2), atrial fibrillation, cardiovascular disease (cardiac and peripheral vascular disease), and chronic obstructive pulmonary disease.

\section{Statistical analysis}

To describe the baseline characteristics and background data of the study population and health care use at the EOL, frequencies and percentages were used for categorical data and mean values with standard deviations (SD) or median values with quartiles (Q25-Q75) for numeric data. To compare the characteristics of SACT and noSACT patients and SACT patients who died within 14 days and 30 days after their last treatment, the MannWhitney $U$ test (numeric variables), Fisher test or z-test (categorical variables) was used. Overall survival (OS) was calculated from the treatment decision date. We used Kaplan Meier estimates to evaluate the survival of patients with SACT versus those with no-SACT. A multivariate Cox proportional hazards model was used to evaluate the effect of chemotherapy, sex, age, stage, disease status, histology, and comorbidities on survival among patients with SACT. The same variables were studied as potential predictors of intensive EOL care; statistical significance was tested with the z-test. Multivariable logistic regression models were constructed to determine factors associated with intensive EOL care. All significance tests were two sided with an $\alpha$-level of 0.05 . Bonferroni corrections were used on multiple comparisons. Patients were censored at the time of the data cut-off date and assumed alive if no national death date was given. All analyses were conducted using Stata 14.2 software.

\section{Results}

\section{Characteristics of the study population and treatment patterns}

A retrospective cohort of patients with lung cancer, who were treated at the North Estonia Medical Centre during the study period from 2015 to 2017, was assembled using the institutional Thoracic Oncology Database (Fig. 1). Patients' baseline characteristics are presented in Table 1. The patients in the SACT group were younger than those who did not receive SACT. A biopsy was performed in almost all patients of the SACT group, whereas it was not possible in $23 \%$ of no-SACT patients. As a result, no histology data was available for $47 \%$ of no-SACT patients vs $15 \%$ of SACT patients. The patients in the no-SACT group had more cardiac comorbidities, whereas the 
Table 1 Baseline and clinical characteristics of the study population

\begin{tabular}{|c|c|c|c|}
\hline & $\begin{array}{l}\text { SACT } \\
(n=489)\end{array}$ & $\begin{array}{l}\text { no-SACT } \\
(n=289) \\
\end{array}$ & $p$ \\
\hline Male & $338(69.1 \%)$ & $219(75.8 \%)$ & 0.049 \\
\hline Female & $151(30.9 \%)$ & $70(24.2 \%)$ & \\
\hline Age at the time of MDT & & & $<0.001$ \\
\hline$\leq 49.9$ & $20(4.1 \%)$ & $5(1.7 \%)$ & \\
\hline $50-64.9$ & $194(39.7 \%)$ & $45(15.6 \%)$ & \\
\hline $65-74.9$ & $183(37.4 \%)$ & $115(39.8 \%)$ & \\
\hline$\geq 75$ & $92(18.8 \%)$ & $124(42.9 \%)$ & \\
\hline median (Q25-Q75) & $66(60-73)$ & $73(67-79)$ & \\
\hline \multicolumn{4}{|l|}{ Biopsy } \\
\hline Yes & $483(98.8 \%)$ & $222(76.8 \%)$ & $<0.0001$ \\
\hline No & $6(1.2 \%)$ & $67(23.2 \%)$ & \\
\hline Histology & & & $<0.001$ \\
\hline adenocarcinoma & $168(34.4 \%)$ & $45(15.6 \%)$ & \\
\hline squamous & $124(25.4 \%)$ & $69(23.9 \%)$ & \\
\hline small cell & $125(25.6 \%)$ & $40(13.8 \%)$ & \\
\hline Other/no malignancy/no histology & $72(14.7 \%)$ & $135(46.7 \%)$ & \\
\hline Stage & & & 0.74 \\
\hline$\|$ & $2(0.4 \%)$ & $0(0 \%)$ & \\
\hline III & $137(28.0 \%)$ & $80(27.7 \%)$ & \\
\hline IV & $350(71.6 \%)$ & $209(72.3)$ & \\
\hline Newly diagnosed & $390(79.8 \%)$ & $252(87.2 \%)$ & 0.008 \\
\hline Recurrence & $99(20.2 \%)$ & $37(12.8 \%)$ & \\
\hline \multicolumn{4}{|l|}{ Time from biopsy to MDT (days) } \\
\hline median (Q25-Q75) & $12(2-27)$ & $8(0-18)$ & 0.0005 \\
\hline$(\min -\max )$ & $(0-3555)$ & $(0-3240)$ & \\
\hline \multicolumn{4}{|l|}{ Palliative radiotherapy } \\
\hline$\leq 3$ months before MDT & $14(2.9 \%)$ & $6(2.1 \%)$ & 0.64 \\
\hline since MDT & $181(37.0 \%)$ & $16(5.5 \%)$ & $<0.001$ \\
\hline \multicolumn{4}{|l|}{ Comorbidities } \\
\hline \multicolumn{4}{|l|}{$\leq 3$ months before MDT } \\
\hline Sepsis & $1(0.2 \%)$ & $2(0.7 \%)$ & 0.56 \\
\hline Bacterial infection & $0(0 \%)$ & $4(1.4 \%)$ & 0.019 \\
\hline Drug-related neutropenia & $0(0 \%)$ & $0(0 \%)$ & \\
\hline Diabetes & $54(11.0 \%)$ & $42(14.5 \%)$ & 0.176 \\
\hline Atrial fibrillation & $49(10.0 \%)$ & $53(18.3 \%)$ & 0.001 \\
\hline Cardiovascular disease & $266(54.4 \%)$ & $187(64.7 \%)$ & 0.005 \\
\hline COPD & $107(21.9 \%)$ & $85(29.4 \%)$ & .02 \\
\hline \multicolumn{4}{|l|}{ since MDT } \\
\hline Sepsis & $52(10.6 \%)$ & $16(5.5 \%)$ & 0.018 \\
\hline Bacterial infection & $44(9.0 \%)$ & $3(1.0 \%)$ & $<0.001$ \\
\hline Drug-related neutropenia & $34(7.0 \%)$ & $0(0 \%)$ & $<0.001$ \\
\hline COPD & $109(22.3 \%)$ & 13 (4.5\%) & .001 \\
\hline
\end{tabular}


patients in the SACT group had more treatment-related complications. In the SACT group, the first cycle of SACT was administered on average 24 days after the treatment decision. The mean number of SACT courses was 6.3 (median 4), and the patients with adenocarcinoma received twice as many SACT courses compared with squamous and small-cell lung cancer patients (Supplemental Table 1).

\section{Overall survival and location of death}

By the study cut-off date, $77 \%$ of SACT patients had died compared with $96 \%$ of no-SACT patients (Table 2). The median OS of no-SACT patients was 1.3 months (Q25-Q75 0.5-3.5), in 58 patients who received no SACT despite the MDT decision median OS was 1.6 months (Q25-Q75 0.7-4.6). In patients who received at least one cycle of SACT OS was 9.1 months (hazard ratio $[\mathrm{HR}]=4.23,95 \% \mathrm{CI}=3.60-5.00, p<0.001$ ), (Fig. 2, Panel a). The OS of patients with adenocarcinoma histology was significantly longer than all other histologies (median OS 13.3 vs 8.1 months, $\mathrm{HR}=0.61,95 \% \mathrm{CI}=$ $0.49-0.76, p<0.001$ ), but there was no difference in the OS between histological subtypes in the no-SACT group $(p=0.951)$, (Fig. 2, Panel b). Among the patients who died during the study period, only $21 \%$ of patients in the no-SACT group died in a hospital (acute care or nursing hospital), whereas $38 \%$ of the SACT group deaths occurred in an acute care hospital and $24 \%$ in a nursing hospital (Table 2). In total, $22 \%$ of patients in the SACT group died in the hospital after they had been admitted via emergency department. In the SACT group, $77 \%$ of the deaths had occurred at the data cut-off date with a median survival of 75 days after the last cycle of SACT (Supplemental Table 1).

Table 2 Mortality and location of death in patients with and without systemic anti-cancer treatment

\begin{tabular}{lll}
\hline & $\begin{array}{l}\text { SACT } \\
(\mathbf{N}=\mathbf{4 8 9})\end{array}$ & $\begin{array}{l}\text { No-SACT } \\
(\mathbf{N}=\mathbf{2 8 9})\end{array}$ \\
\hline Died $\leq 14$ days since MDT, N (\%) & $4(0.8)$ & $68(23.5)$ \\
Died $\leq 30$ days since MDT, N (\%) & $12(2.5)$ & $118(40.8)$ \\
Died $\leq 30$ days since last cycle, N (\%) & $72(14.7)$ & NA \\
Died at data cut off, N (\%) & $376(76.9)$ & $279(96.5)$ \\
Place of death & & \\
Acute care hospital $^{\mathrm{a}}$ & $144(38.3)$ & $41(14.2)$ \\
Following ED attendance $^{\mathrm{b}}$ & $82(21.8)$ & $28(9.7)$ \\
$\quad$ Nursing home & $90(23.9)$ & $20(6.9)$ \\
$\quad$ Out-of-hospital & $142(37.8)$ & $218(75.4)$ \\
\hline
\end{tabular}

Abbreviations: SACT Systemic anti-cancer treatment, ED

Emergency department

${ }^{a}$ Died at hospital when the date of last claim was the date of death plus 1 day

${ }^{b}$ Died at hospital through ED visit when the last claim started with the date of ED claim. 9 patients in the no-SACT arm and 30 patients in the SACT arm died on same or next day as ED visit

\section{Intensity of care at the EOL}

Any one of the following outcomes - hospitalisation, ED visit, ICU admission, radiotherapy or SACT (except noSACT) - occurred during the final 30 days of life in $70 \%$ of the SACT group and $44 \%$ of the no-SACT group (Table 3). 0.8 and $2.5 \%$ of SACT patients had died within 14 and 30 days after the treatment decision, respectively, compared with the 24 and $41 \%$ in the noSACT group (Table 2). Only $22(7.6 \%)$ of patients in the no-SACT group received palliative RT, of whom seven (31.8\%) died within 30 days (Table 2). In total, 195 $(39.9 \%)$ patients in the SACT group received radiotherapy, but only 12 patients (6.2\%) received radiotherapy within the final 30 days of life. The 63 patients who received only one course of SACT had a similar OS to patients with no-SACT $(\mathrm{HR}=0.97,95 \% \mathrm{CI}=0.73-1.28$, $p=0.8$ ), (Fig. 2, Panel a), indicating no benefit from systemic treatment in these patients. An additional $37 \mathrm{pa}$ tients died within 30 days after the last cycle of SACT due to disease progression (Table 4). Combined, this results in a total of 100 patients for whom the final cycle of SACT undergone did not provide benefit and may be considered overtreatment. Intensive EOL care in the last 30 days of life is more probable among patients in the SACT group (odds ratio $[\mathrm{OR}]=3.58,95 \% \mathrm{CI}=2.54$ $5.04, p<0.001)$, especially in those with a stage IV disease $(\mathrm{OR}=1.89,95 \% \mathrm{CI}=1.31-2.71, p=0.001)$.

\section{SACT-related toxicity and 14- and 30-day mortality}

The SACT patients received on average 6.3 (median 4) cycles of systemic chemotherapy and the median duration of treatment was 78 days, except for patients with adenocarcinoma (on average 9 courses over 135 days; $p<0.001$ ), (Supplemental Table 1). In the SACT group, 10.6 and $7.0 \%$ of patients developed at least one case of sepsis or neutropenia, respectively (Table 1 ). In the SACT group, 33 patients (6.7\%) died within 14 days and 72 patients (14.7\%) within 30 days of the last SACT cycle. $11.2 \%$ of the deceased were hospitalised due to sepsis and $2.9 \%$ had neutropenia in the final 30 days (Table 3). In total, $46 \%$ of early deaths (in 14 days) occurred after the first cycle of SACT. 22.2, 6.9 and 11.1\% of patients with 30-day mortality after SACT developed sepsis, bacterial infection or drug-related neutropenia, respectively, but were less frequent in patients who died more than 30 days after the last cycle of SACT (Supplemental Table 2). In the multivariate Cox proportional hazard models, male sex, age younger than 69 years, histology other than adenocarcinoma had a significant adverse impact on survival (Table 5). We then aimed to identify the cause of death in patients with early SACTrelated mortality. Patients who died within 14 days after SACT were more likely to die after the first cycle $(p=$ 0.03 ), to have one episode of neutropenia before the last 
- - SACT 1 -- SACT $>=3$ no-SACT - SACT
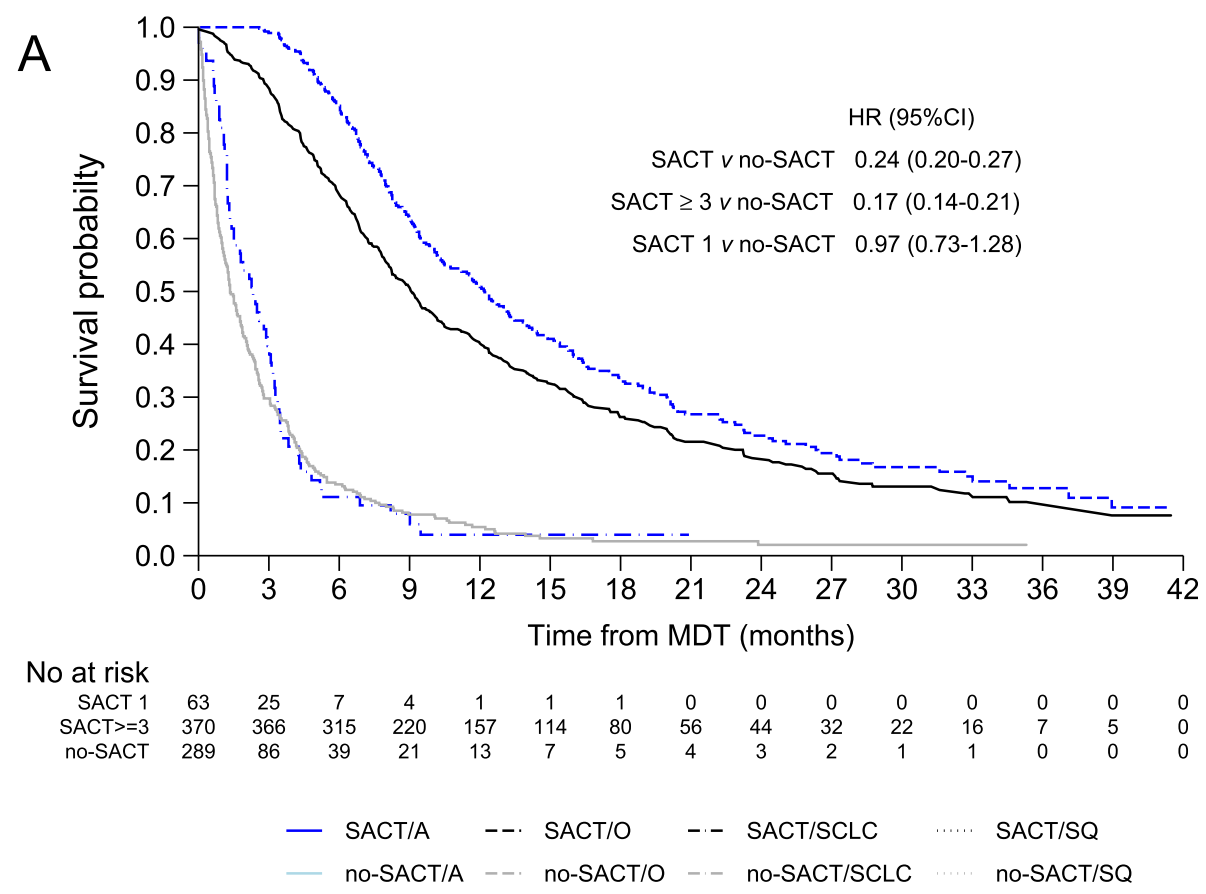

B

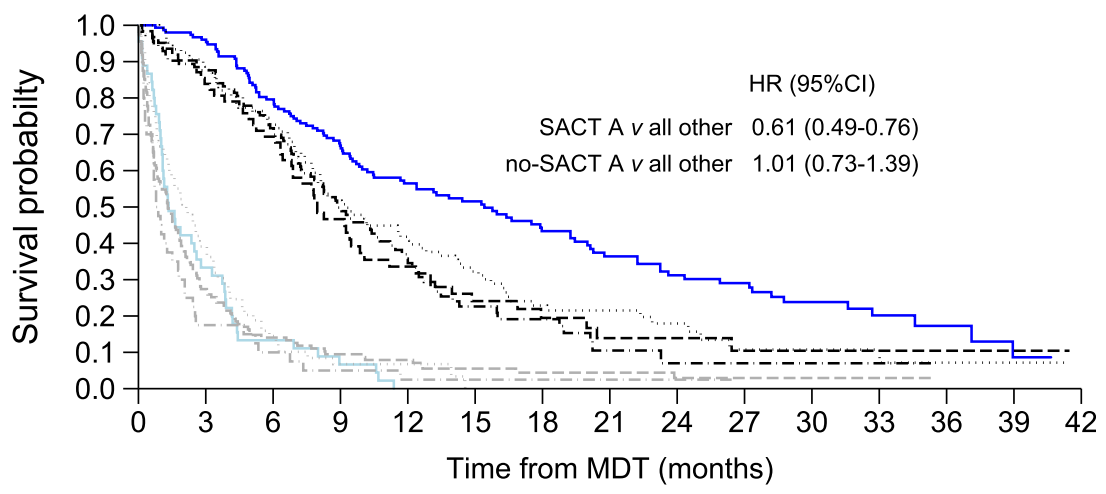

$\begin{array}{rccccc}\text { No at risk } & & & & & \\ \text { SACT/A } & 152 & 146 & 121 & 94 & 71 \\ \text { SACT/O } & 62 & 52 & 43 & 25 & 8 \\ \text { SACT/SCLC } & 113 & 99 & 81 & 51 & 29 \\ \text { SACT/SQ } & 106 & 94 & 77 & 54 & 40 \\ \text { no-SACT/A } & 45 & 15 & 6 & 3 & \\ \text { no-SACT/O } & 135 & 37 & 19 & 12 & \\ \text { no-SACT/SCLC } & 40 & 7 & 4 & 2 \\ \text { no-SACT/SQ } & 69 & 27 & 10 & 4\end{array}$

Fig. 2 Overall survival in the study population (panel a) according to number of SACT cycles and (panel b) histology. Abbreviations: SACT, systemic anti-cancer treatment; MDT, multidisciplinary tumour board; A, adenocarcinoma; O, all other histologies combined; SCLC, small cell lung cancer; SQ, squamous cell; HR, hazard ratio

cycle $(15.2 \%$ vs $2.6 \%, p=0.09)$, to develop neutropenia or pancytopenia after the last cycle $(27.3 \%$ vs $12.8 \%, p=$ $0.145)$, to be admitted to the ICU before death $(p=$ $0.003)$ and to die due to infection $(p=0.09)$ (Table 4).

\section{Discussion}

To our knowledge, this is the first study to evaluate EOL cancer care in Estonia and in Eastern Europe. Our results confirm that a significant proportion of patients with advanced lung cancer continue to receive intensive care near death. Nearly $15 \%$ of patients in the current study died within 30 days after the last cycle of SACT. Infectious complications and neutropenia were responsible for over one in five of these deaths. These findings are particularly important, as chemotherapy in combination with immunotherapy is the currently recommended first line of treatment in most patients with advanced lung cancer.

Patients with a poor performance status do not benefit from chemotherapy $[9,15]$. In our study, patients with the treatment decision no-SACT had a poor prognosis 
Table 3 The intensity of care in the final 30 days of life in deceased patients

\begin{tabular}{|c|c|c|c|c|c|}
\hline \multirow[t]{2}{*}{ Care measure } & \multicolumn{2}{|c|}{$\begin{array}{l}\text { SACT } \\
(N=376)\end{array}$} & \multicolumn{2}{|c|}{$\begin{array}{l}\text { No-SACT } \\
(N=279)\end{array}$} & \multirow[t]{2}{*}{$p^{c}$} \\
\hline & $\mathbf{N}$ & $\%$ & $\mathbf{N}$ & $\%$ & \\
\hline Any hospitalization & 237 & 63.0 & 110 & 39.4 & $<0.001$ \\
\hline Hospitalizations $^{a}$ & 186 & 49.5 & 99 & 35.5 & $<0.001$ \\
\hline Sepsis & 42 & 11.2 & 11 & 3.9 & 0.0064 \\
\hline Bacterial infection & 14 & 3.7 & 1 & 0.4 & 0.0352 \\
\hline Neutropenia & 11 & 2.9 & 0 & 0.0 & - \\
\hline ED visit & 187 & 49.7 & 87 & 31.2 & $<0.001$ \\
\hline ICU admission & 49 & 13.0 & 36 & 12.9 & 0.99 \\
\hline SACT & 72 & 19.1 & - & - & - \\
\hline RT & 12 & 3.2 & 7 & 2.5 & 0.99 \\
\hline Composite of measures $^{b}$ & 263 & 69.9 & 122 & 43.7 & $<0.001$ \\
\hline All 5 (SC 4) & 0 & 0.0 & 0 & 0.0 & \\
\hline None & 113 & 30.1 & 157 & 56.3 & $<0.001$ \\
\hline
\end{tabular}

Abbreviations: SACT Systemic anti-cancer treatment, ED Emergency department, ICU Intensive care unit, RT Radiotherapy

aHospitalizations without sepsis, bacterial infection or neutropenia

${ }^{\mathrm{b}}$ Any of the following outcomes: hospitalization, ED visit, ICU admission, SACT (except SC), or RT

${ }^{\mathrm{C}}$ Tested by z-test with Bonferroni correction

with a median OS of 1.3 months. Due to the lack of EOL services, they were frequently hospitalised through ED visits near death. $78 \%$ of the deceased in the no-SACT group died outside hospital (acute or nursing hospital). There was no possibility to collect data on care and costs paid by a family, including home-based care. However, our findings indicate very limited provision of organised health care services to patients deemed ineligible for active oncological treatment. It is well recognised that EOL care is a subject for considerable policy differences, which also exist among developed countries. For instance, in the US and the Netherlands, the lowest proportion of cancer patients died in acute care hospitals (less than 30\%), whereas $77 \%$ of cancer patients in France die in hospitals [16, 17]. Previous studies have not reported EOL data depending on patients' eligibility for active oncological treatment; however, this likely affects who provides EOL care and how it is provided. Our study demonstrated that there is an urgent need to increase EOL supportive care services in Estonia, particularly for patients not eligible for active treatment.

The median OS of patients in this study who received at least one cycle of SACT was 9.1 months. One-third of patients who opted for SACT accounted for potential overtreatment, including $63(13 \%)$ patients who received only one cycle of SACT, 37 (7\%) patients who died of progression after receiving SACT in the final 30 days and 58 (11\%) patients who never received systemic treatment despite the decision. Timely access to SACT is an important aspect of cancer care, particularly affecting patients with high disease and symptom burden. The median time from the diagnosis to the start of systemic treatment was approximately 1 month in the current study. Prioritisation of patients eligible for SACT is necessary to reduce delays in treatment initiation and improve outcome. Of those who did not undergo SACT OS was 1.3 months. 22 (7.6\%) of these patients received palliative radiotherapy with seven $(31.8 \%)$ dying within 30 days. In light of their very short survival and the anticipated time to treatment benefit, it is unlikely that these patients will have benefitted from radiotherapy.

We chose previously reported indicators of the intensity of cancer care relevant to adult patients with solid tumours [3-8]. A composite measure for intensive EOL care was received by $70 \%$ of the deceased SACT patients and $44 \%$ of the no-SACT patients in the current study.

Table 4 Cause of death in patients who died within 14 days or during 15-30 days of systemic anti-cancer treatment

\begin{tabular}{|c|c|c|c|c|}
\hline Characteristics & $\begin{array}{l}\leq 14 \text { days } \\
N=33\end{array}$ & $\begin{array}{l}15-30 \text { days } \\
N=39\end{array}$ & $\begin{array}{l}\text { Total } \\
N=72\end{array}$ & $p$ \\
\hline Died after 1st SACT cycle, N (\%) & $16(48.5)$ & $9(23.1)$ & $25(34.7)$ & 0.03 \\
\hline Total SACT cycles (median, range) & $2(1-13)$ & $4(1-17)$ & $3(1-17)$ & 0.06 \\
\hline NEU before last cycle, N (\%) & $5(15.2)$ & $1(2.6)$ & $6(8.3)$ & 0.09 \\
\hline GCS-GF ${ }^{a}$ & $3(9)$ & $3(7.7)$ & $6(8.3)$ & 1 \\
\hline NEU/PAN after last cycle & $9(27.3)$ & $5(12.8)$ & $14(19.4)$ & 0.145 \\
\hline ICU before death & $15(45.5)$ & $5(12.8)$ & $20(27.8)$ & 0.003 \\
\hline Cause of death, N (\%) & & & & 0.09 \\
\hline CV & $3(9.1)$ & $3(7.7)$ & $6(8.3)$ & \\
\hline INF & $9(27.3)$ & $7(18)$ & $16(22.2)$ & \\
\hline PD & $13(39.4)$ & $26(66.7)$ & $39(54.2)$ & \\
\hline SUDDEN & $8(24.2)$ & $3(7.7)$ & $11(15.3)$ & \\
\hline
\end{tabular}

Abbreviations: SACT Systemic anti-cancer treatment, NEU Neutropenia, INF Infection, PD Progression, GCS-GF Granulocyte colony stimulating growth factor, PAN Pancytopenia, ICU Intensive care unit admission, CV Cardiovascular, SUDDEN sudden death or unknown with good performance status at the time of last SACT ${ }^{\mathrm{a}} \mathrm{GCS}-\mathrm{GF}$ primary prophylaxis before last cycle. Values in bold are significant at $p<0.05$ 
Table 5 Multivariate Cox proportional hazards models of survival among patients who received systemic anti-cancer treatment

\begin{tabular}{|c|c|c|c|}
\hline Characteristic & $\begin{array}{l}\text { Unadjusted } \\
\text { HR }(95 \% \mathrm{Cl})\end{array}$ & $\begin{array}{l}\text { Adjusted }^{\mathrm{a}} \\
\mathrm{HR}(95 \% \mathrm{Cl})\end{array}$ & $\begin{array}{l}\text { Adjusted } \\
p\end{array}$ \\
\hline \multicolumn{4}{|l|}{ Sex } \\
\hline Female & 1 & 1 & \\
\hline Male & $1.56(1.24-1.96)$ & $1.38(1.08-1.76)$ & 0.011 \\
\hline \multicolumn{4}{|l|}{ Age } \\
\hline$\leq 49$ & 1 & 1 & \\
\hline $50-59$ & $2.11(1.14-3.89)$ & $2.2(1.18-4.08)$ & 0.013 \\
\hline $60-69$ & $1.80(1.00-3.25)$ & $1.87(1.02-3.4)$ & 0.042 \\
\hline $70-79$ & $1.45(0.80-2.64)$ & $1.58(0.86-2.92)$ & 0.14 \\
\hline $80 \geq$ & $1.67(0.84-3.31)$ & $1.93(0.96-3.88)$ & 0.065 \\
\hline \multicolumn{4}{|c|}{ Comorbidities (yes vs no) } \\
\hline Diabetes & $0.94(0.71-1.26)$ & $1.06(0.78-1.43$ & .716 \\
\hline Cardiovascular & $0.84(1.05-1.43)$ & $0.89(0.69-1.14)$ & .347 \\
\hline Atrial fibrillation & $1.00(0.78-1.30)$ & $0.99(0.75-1.31)$ & .956 \\
\hline COPD & $0.99(0.80-1.25)$ & $0.9(0.71-1.13)$ & 0.353 \\
\hline \multicolumn{4}{|l|}{ Disease status } \\
\hline Newly diagnosed & $1.14(0.88-1.47)$ & $1.26(0.96-1.65)$ & .009 \\
\hline Recurrence & 1 & 1 & \\
\hline \multicolumn{4}{|l|}{ Stage } \\
\hline$\|$ & $0.87(0.21-3.52)$ & $1.18(0.28-4.98)$ & .824 \\
\hline III & 1 & 1 & \\
\hline IV & $0.96(0.76-1.20)$ & $1.11(0.87-1.4)$ & .402 \\
\hline \multicolumn{4}{|l|}{ Histology } \\
\hline Adenocarcinoma & 1 & 1 & \\
\hline Squamous & $1.58(1.21-2.06)$ & $1.54(1.15-2.08)$ & .004 \\
\hline SCLC & $1.63(1.19-2.24)$ & $1.48(1.07-2.05)$ & .019 \\
\hline Other & $1.70(1.29-2.24)$ & $1.59(1.18-2.14)$ & .002 \\
\hline \multicolumn{4}{|c|}{ Other cancer treatment } \\
\hline Radiotherapy & $1.02(0.83-1.26)$ & $0.9(0.72-1.12)$ & .334 \\
\hline
\end{tabular}

$H R$ Hazard ratio, $\mathrm{Cl}$ Confidence interval, $p$ Probability, COPD Chronic obstructive pulmonary disease, SCLC Small cell lung cancer ${ }^{a}$ Adjusted on all patient and disease related variables in the table. Values in bold are significant at $P<.05$

Moreover, $66 \%$ of the total 489 SACT patients had at least one ED visit after the initiation of SACT, including 30 patients who died on the same or next day as the ED visit. Our findings are in line with those from Canada, where $62 \%$ of patients with lung cancer had at least one ED visit in the last 30 days [17]. In the US, ICU admissions near death were twice as high as those in six other developed countries, with $27 \%$ of adult cancer patients being admitted to the ICU in the last 30 days [17]. In our study, $13 \%$ of patients in both the SACT and noSACT groups experienced ICU admission. We found no evident pattern between patient characteristics and the likelihood of receiving intensive EOL care. Future research should focus on causes leading to ED visits, whether these could be avoided by improving access to oncology services directly $24 / 7$ and palliative and hospice care.

Of the various intensive EOL care measures, the use of chemotherapy near death has been studied most extensively. Chemotherapy use in the last 30 days of life ranged from $4.8 \%$ (Norway) to $10.6 \%$ (US) and $12.7 \%$ (Belgium) [17]. Among various solid tumours, patients with lung cancer were more likely to receive chemotherapy at the EOL [18]. At the data cut-off date, 19\% of the deceased patients in our study had received SACT in the final 30 days of life, similar to the rate reported in France [16]. In England, 30-day mortality after SACT was higher in patients with lung cancer compared to patients with breast cancer, with a considerable difference in curative (3\%) and palliative (10\%) treatments [19]. Infectious complications were significant predictors for early SACT-related death and hospitalisations in our study (Supplemental Table 2). Among EOL hospitalisations, $11 \%$ were due to sepsis and 3\% of patients had neutropenia. Patients who died within 14 days after SACT were more likely to die due to neutropenia and infection, whereas patients who died within 15-30 days after the last cycle of SACT were more likely to die of progressive disease. It has previously been shown that cancer-related neutropenia accounts for a substantial amount of the total cancer-related hospitalisation costs [20]. Using the same dataset for our ongoing study, we found that neutropenia and severe infection resulted in median hospital stay of 11 days in our hospital. ASCO's guideline for the management of neutropenia generally recommends primary prophylaxis when the risk of neutropenia is high (>20\%) [21]. In recent decade, several biosimilar GCSGF products have been approved in the $\mathrm{EU}$ and in rest of the world, making the use of neutropenia prophylaxis more cost-effective. Our findings raise the possibility that a lower threshold for the prophylactic use of GCSGF may be needed for lung cancer.

Our study has several limitations. Firstly, it was a single centre retrospective cohort study with a relatively small sample size. Secondly, our study was based on the data of health service use and we had no information on the performance status of patients. However, for those patients who died within 30 days after SACT, a detailed review of electronic medical records was conducted and the probable cause of death identified. The strengths of this study include: a) universal insurance coverage in Estonia, meaning our results capture all health care services provided to patients; b) systemic treatment of lung cancer for the whole population in the catchment area is delivered only in this specific cancer centre, thus the study cohort includes all cancer patients; c) homogenous 
population, eg patients with advanced lung cancer from the routine clinical database; d) homogenous systemic treatment, as ALK-inhibitors and immunotherapy were not reimbursed at the time of the study; e) most recent study period; f) the cause of death was evaluated through detailed review of electronic medical records.

\section{Conclusions}

A significant proportion of patients with advanced lung cancer continue to receive intensive care near death with a negative health impact. Progressive disease was the main cause of death. Chemotherapy is the cornerstone of treatment for advanced lung cancer and our results illustrate that careful selection of patients for SACT is important. Deaths due to neutropenia and infectious complications constituted a clinically significant proportion of those dying within 30 days. Combined with the ED attendances shown here this finding supports the need for improved support for patients on SACT. Finally, despite evidence of careful selection for SACT in many cases, our results reflect the patterns of the EOL care of lung cancer in Estonia, where the availability of palliative health care services and hospice care must be increased to improve resource use and patient-oriented care.

\section{Abbreviations}

ED: Emergency department; EOL: End of life; ICU: Intensive care unit; GCSGF: Granulocyte colony stimulating growth factor; MDT: Multidisciplinary tumour board; OS: Overall survival; QoL: Quality of life; SACT: Systemic anticancer treatment

\section{Supplementary Information}

The online version contains supplementary material available at https://doi. org/10.1186/s12885-021-07992-5

Additional file 1: Supplemental Table 1. Use of systemic anti-cancer treatment in patients with advanced lung cancer. Supplemental Table 2. Myelotoxicity and infectious complications in patients with and without 14- and 30-day mortality after last cycle of systemic anti-cancer treatment

\section{Acknowledgements}

We thank Sirly Lätt from the Estonian Health Insurance Fund and Sirje Kaarna from the North Estonia Medical Centre for conducting the data linking.

\section{Authors' contributions \\ $\mathrm{KO}$ contributed to the concept and design, collected and analysed data, wrote the main part of the manuscript. HP analysed the data, performed statistical analysis and contributed to the manuscript. Kl collected the data, contributed to the data interpretation and manuscript writing. RAK contributed to the concept, interpretation of the data and manuscript writing. All authors have read and approved the manuscript.}

\section{Funding}

The study was supported by the research grant from the North Estonia Medical Centre. The funding body played no role in the design of the study and collection, analysis, and interpretation of data and in writing the manuscript.
Availability of data and materials

Datasets analyzed are available from the corresponding author.

\section{Declarations}

Ethics approval and consent to participate

Tallinn Ethics Committee for Medical Research (no. 1972) approved the study and waived the need for informed consent. The approval included permission to access the raw data from Thoracic Oncology Database.

\section{Consent for publication}

Not applicable.

\section{Competing interests}

Authors have no conflicts of interests in regard to this publication.

\section{Author details}

'Department of Chemotherapy, Clinic of Haematology and Oncology, North Estonia Medical Centre, J. Sütiste tee 19, 13419 Tallinn, Estonia. ${ }^{2}$ Institute of Family Medicine and Public Health, Tartu University, Tartu, Estonia.

${ }^{3}$ Pharmacy, North Estonia Medical Centre, Tallinn, Estonia.

Received: 25 March 2020 Accepted: 28 February 2021

Published online: 15 March 2021

\section{References}

1. Dasch B, Kalies H, Feddersen B, Ruderer C, Hiddemann W, Bausewein C. Care of cancer patients at the end of life in a German university hospital: A retrospective observational study from 2014. PLoS One. 2017;12:e0175124.

2. Heikkilä R, Kaasa S. Chemotherapy in end-of-life care. Ann Oncol. 2017;28: 684-5.

3. Earle CC, Park ER, Lai B, Weeks JC, Ayanian JZ, Block S. Identifying potential indicators of the quality of end-of-life cancer care from administrative data. J Clin Oncol. 2003;21:1133-8.

4. Earle CC, Landrum MB, Souza JM, et al. Aggressiveness of cancer care near the end of life: is it a quality-of-care issue? J Clin Oncol. 2008;26:3860-6.

5. Barbera L, Seow H, Sutradhar R, Chu A, Burge F, Fassbender K, et al. Quality indicators of end-of-life Care in Patients with Cancer: what rate is right? J Oncol Pract. 2015;11:e279-87.

6. Kassam A, Sutradhar R, Widger $K$, et al. Predictors of and trends in highintensity end-of-life care among children with Cancer: a population-based study using health services data. J Clin Oncol. 2017;35:236-42.

7. Wang R, Zeidan AM, Halene S, et al. Health care use by older adults with acute myeloid leukemia at the end of life. J Clin Oncol. 2017:35:3417-24.

8. Taylor JS, Rajan SS, Zhang N, et al. End-of-life racial and ethnic disparities among patients with ovarian Cancer. J Clin Oncol. 2017:35:1829-35.

9. Schnipper LE, Smith TJ, Raghavan D, Blayney DW, Ganz PA, Mulvey TM, et al. American society of clinical oncology identifies five key opportunities to improve care and reduce costs: the top five list for oncology. J Clin Oncol. 2012:30:1715-24.

10. Ho TH, Barbera L, Saskin R, Lu H, Neville BA, Earle CC. Trends in the aggressiveness of end-of-life cancer care in the universal health care system of Ontario, Canada. J Clin Oncol. 2011:29:1587-91.

11. Temel JS, Greer JA, Muzikansky A, Gallagher ER, Admane S, Jackson VA, et al. Early palliative care for patients with metastatic non-small-cell lung cancer. N Engl J Med. 2010;363:733-42.

12. Whitney RL, Bell JF, Tancredi DJ, Romano PS, Bold RJ, Wun T, et al. Unplanned hospitalization among individuals with Cancer in the year after diagnosis. J Oncol Pract. 2019:15:e20-9.

13. Mor V, Wagner TH, Levy C, Ersek M, Miller C, Gidwani-marszowski R, et al. Association of Expanded VA hospice care with aggressive care and cost for veterans with advanced lung Cancer. JAMA Oncol. 2019;5(6):810-6.

14. Innos K, Oselin K, Laisaar T, Aareleid T. Patterns of survival and surgical treatment in lung cancer patients in Estonia by histologic type and stage, 1996-2016. Acta Oncol. 2019;58(11):1-8

15. Prigerson HG, Bao Y, Shah MA, Paulk ME, LeBlanc TW, Schneider BJ, et al Chemotherapy use, performance status, and quality of life at the end of life. JAMA Oncol. 2015:1:778.

16. Rochigneux P, Raoul $J$, Beaussant Y, Aubry R, Goldwasser F, Tournigand C, et al. Use of chemotherapy near the end of life: what factors matter? Ann Oncol. 2017;28:809-17. 
17. Bekelman JE, Halpern SD, Blankart CR, Bynum JP, Cohen J, Fowler R, et al. Comparison of site of death, health care utilization, and hospital expenditures for patients dying with Cancer in 7 developed countries. JAMA. 2016;315:272.

18. Fang P, Jagsi R, He W, Lei X, Campbell EG, Giordano SH, et al. Rising and falling trends in the use of chemotherapy and targeted therapy near the end of life in older patients with Cancer. J Clin Oncol. 2019;37:1721-31.

19. Wallington M, Saxon EB, Bomb M, Smittenaar R, Wickenden M, McPhail S, et al. 30-day mortality after systemic anticancer treatment for breast and lung cancer in England: a population-based, observational study. Lancet Oncol. 2016;17:1203-16.

20. Tai E, Guy GP, Dunbar A, Richardson LC. Cost of Cancer-related neutropenia or fever hospitalizations, United States, 2012. J Oncol Pract. 2017;13:e552-61.

21. Smith TJ, Bohlke K, Lyman GH, Carson KR, Crawford J, Cross SJ, et al. Recommendations for the use of WBC growth factors: American Society of Clinical Oncology clinical practice guideline update. J Clin Oncol. 2015;33: 3199-212.

\section{Publisher's Note}

Springer Nature remains neutral with regard to jurisdictional claims in published maps and institutional affiliations.

Ready to submit your research? Choose BMC and benefit from:

- fast, convenient online submission

- thorough peer review by experienced researchers in your field

- rapid publication on acceptance

- support for research data, including large and complex data types

- gold Open Access which fosters wider collaboration and increased citations

- maximum visibility for your research: over $100 \mathrm{M}$ website views per year

At $\mathrm{BMC}$, research is always in progress.

Learn more biomedcentral.com/submissions 